\title{
Adapting Television Satellite Dish for Low-Temperature Solar Thermal Application: Experimental Evaluation
}

\author{
Adetifa Babatunde O., Salami Wasiu D., Samuel Taiwo M., Babalola Ayoola A and Sosanya Abolade O. \\ Department of Agricultural Engineering, Faculty of Engineering, College of Engineering and Environmental Studies, Olabisi \\ Onabanjo University, 112104, Ibogun, Ifo, Ogun State, Nigeria
}

\begin{tabular}{l} 
Article Info \\
\hline Article history: \\
Received Dec 13, 2018 \\
Revised Dec 16, 2018 \\
Accepted Dec 21, 2018 \\
\hline
\end{tabular}

\section{Keyword:}

Solar cooker

Parabolic

Stagnation temperature

Temperature change

TV cable dish

\begin{abstract}
Digital television broadcasting is currently becoming popular and as a result, the purchase of television cable dishes and other accessories are on the rise. Abandoned television satellite dishes continue to litter our environment due to obsolescence. Finding alternative use stands as a control measure for this inevitable environmental degradation. This paper, therefore, investigates the adaptation for low temperature solar thermal application. The TV satellite dish selected for this study has a diameter of $33.9 \mathrm{~cm}$, depth of $9 \mathrm{~cm}$ and a focal point of $31.2 \mathrm{~cm}$. The components added to the dish include; a reflective surface, pot stand, adjustable chain, dish support stand and base, control arm. This system was used in carrying out stagnation test on three different types of pots (aluminium, iron and stainless steel pots) positioned at the focal point. Other performance parameters studied include; standard stagnation temperature (SST) and the rate of change of pot temperature. The maximum stagnation temperatures attained by the inside of the iron, aluminium and stainless steel pots were 68,80 and $82{ }^{\circ} \mathrm{C}$ respectively after 10,13 and 40 minutes respectively; while their respective maximum SST were 100, 57 and $50{ }^{\circ} \mathrm{C}$. The maximum temperature change inside the iron, aluminium and stainless steel pots were above 9,12 and $10^{\circ} \mathrm{C} / \mathrm{min}$. The result gathered shows that this system will be suitable for lower temperature applications like pasteurization, sterilization, household water heating, etc.
\end{abstract}

\section{Corresponding Author:}

Adetifa, Babatunde O., Department of Agricultural Engineering, Faculty of Engineering, College of Engineering and Technology, Olabisi Onabanjo University, 112104, Ibogun, Ifo, Ogun State, Nigeria.

Email: olusola.adetifa@oouagoiwoye.edu.ng

\section{Introduction}

Solar energy is the major source of power for the earth's ecosystem, which can be harnessed for thermal and electrical applications. It provides a renewable, low carbon, and an attractive source of energy which mitigates climate change [1], consequently, reducing the consumption of non-renewable energy sources which has increased due to high energy demand [2]. The sun radiates around $9 \mathrm{MJ}$ of energy which is equivalent to the amount of energy required to power a thermal power plant [3]. In addition, the sun strikes an area of $1 \mathrm{~m}^{2}$ of the earth's surface with about $1 \mathrm{~kW}$ of energy [4].

The earth receives $5.4 \times 10^{24}$ joules of solar energy annually, which is approximately equivalent to 30,000 times the energy consumed presently [5]. Nigeria receives an average daily solar radiation around $7.0 \mathrm{kWh} / \mathrm{m}^{2}$ in the northern part and approximately $3.5 \mathrm{kWh} / \mathrm{m}^{2}$ in the coastal latitudes [6], while Makurdi has a monthly 
average daily global solar radiation around $263 \mathrm{~W} / \mathrm{m}^{2}$ [7]. The intensity of solar radiation has also been assessed by several studies across different regions [8-12].

Solar energy has been harnessed for several applications. Solar energy can supply or supplement several farm energy requirements for applications like; crop/grain drying, space/water heating, greenhouse heating, rural electricity supply and water pumping systems [13] [14]. Solar energy can also be applied in drying animal dung for manure, animal house lighting, food storage, storage of drugs and vaccine, water treatment, egg incubation, chick brooding and chicken growing, animal production, etc. [15]. Other applications include solar air conditioning system [16]; solar furnaces, solar desalination systems and solar thermal power systems [17]; hot water solar oven [18]; solar refrigeration [19]; parabolic solar steam generator [20]; etc.

One of the major applications of solar thermal energy is solar cooking. Solar cooking is not a new technology and its components and performance has been improved on over the years leading to the various designs. Some of the common types of solar cookers include; the box-type, foldable panel type, parabolic concentrator type, indirect type, etc. Unlike the box-type solar cookers which trap heat in a confined box, parabolic concentrator solar cookers focus the solar radiation onto the pot [21]. Generally, solar concentrating collectors direct solar radiation from a larger field to a small receiving area where it is converted into other forms of energy [22].

Mohammed [23] developed a parabolic dish solar thermal cooker having aperture $1.8 \mathrm{~m}$ diameter, $29.0 \mathrm{~cm}$ depth and $69.8 \mathrm{~cm}$ focal length. The cooker which was designed to cook food equivalent of $12 \mathrm{~kg}$ of dry rice per day cooked $3.0 \mathrm{~kg}$ of rice within $90-100$ minutes. The design evaluated by Gavisiddesha et al.[24] which has a diameter of $1.4 \mathrm{~m}, 0.4 \mathrm{~m}$ in depth and a focal length of $0.30 \mathrm{~m}$ had a maximum pot temperature of 139.45 ${ }^{\circ} \mathrm{C}$ during an ambient temperature of $39.5{ }^{\circ} \mathrm{C}$.

Dasin [25] used the new world standard procedure for testing solar cookers to determine the thermal performance of parabolic concentrating solar cooker. The standard stagnation temperature obtained was 149.8 ${ }^{\circ} \mathrm{C}$ at maximum average beam radiation of $584.1 \mathrm{~W} / \mathrm{m}^{2}$. The standardized unattended cooking time was 15.56 minutes at $540 \mathrm{~W} / \mathrm{m}^{2}$, while the overall efficiency was $17.5 \%$. Dasin et al. [26] carried out a complete heat transfer analysis of a parabolic concentrator solar cooker. Three different convective heat transfer process taking place in the system were correlated. The flow condition of air in all the three cases of convection is laminar with Rayleigh number of the order of 106 (maximum) within the range of operating temperature of 297 to $400 \mathrm{~K}$.

In finding a way to boost the performance of parabolic concentrators, Dandakouta et al., [27] designed and constructed a compound parabolic concentrating (CPC) solar cooker fitted with a booster mirror whose angle can be adjusted. After experimental evaluation of the system, it was observed that the fitting of booster mirror led to an increase in solar irradiance which produced $2.36 \%$ and $8.75 \%$ increase in the absorber and water temperature respectively. The maximum contribution of the booster to the performance of the solar cooker occurred at an angle of $90^{\circ}$ and was minimal at angles above $105^{\circ}$.

Several materials can be used for the solar parabolic concentrators, but one of the cheapest materials used is adapting satellite dishes. In Nigeria, satellite channels have more viewership than terrestrial stations [28]. In fact, there are around 200 million satellite TV subscribers in the world, implying that the number of satellite dishes in the world is more than 200 million. Many of these satellite TV dishes end up in landfills [29]. Often times, TV satellite dishes are not removed, disposed or reused when a new one is purchased, therefore, there are several houses with close to four unused dishes on their roof [30]. There is, consequently, a need to find an alternative use for these dishes.

Prado et al. [31] used a satellite dish as a solar dish concentrator for desalting water, while Sandru [32] described a low-cost procedure of building a solar furnace which comprises an array of four satellite dishes covered with mirrors, controlled by an electronic circuit via a motor powered from some solar cells. Hijazi [33] designed a low cost parabolic solar dish concentrator with small-to-moderate size for direct electricity generation for rural areas.

The aim of this study is, therefore, to adopt a television cable dish to a parabolic concentrator solar cooker and evaluate its performance. This was be achieved by converting a TV cable dish to a solar cooker; carrying out an experimental evaluation of the parabolic solar cooker using different pots and investigating the effect of the pots on some thermal performance parameters of the parabolic solar cooker. 


\section{Materials and Methods}

\subsection{System Description}

The type of solar thermal application used in this study is a solar cooker used in water heating. The solar cooker used for this study is a parabolic concentrator whose pot is positioned at its focal point. A cable satellite dish (DSTV) was improvised. A stand was fabricated for the dish. Aluminium foils were used as the reflector. The cooking pots were painted black and positioned at the focal point of the dish with the aid of a rod and rope (with adjustable length). The focal point (F) of the reflector should be at the bottom of the cooking pot. This was estimated using (1).

$$
\mathrm{y}^{2}=4 \mathrm{ax}
$$

Where " $y$ " is the diameter of the dish, " $x$ " is the depth and "a" represents the focal point of the dish.

Table 1 shows the component part of a parabolic solar cooker. A TV cable satellite dish was adapted as a parabolic concentrator so as to find another use for unused dishes. The reflector used was aluminium foil three rolls of aluminium foils were used to cover the TV cable dish. The pot stand was made with an iron rod so as to hold the pot. An adjustable chain was installed which adjusts the pot and the pot stand so as to get the correct focal point. The dish was supported on an adjustable stand which was connected to a base. This system also has a concentrator control arm which rotates the dish for sun tracking.

Table 1: Component part of a parabolic solar cooker

\begin{tabular}{ccc}
\hline S/N & ITEMS & QTY \\
\hline 1 & Reflector & 3 rolls \\
2 & Pot stand & 1 \\
3 & Parabolic concentrator & 1 \\
4 & Adjustment chain & 1 \\
5 & Stand support & 1 \\
6 & Base stand & 1 \\
7 & Iron rod & 1 \\
8 & Control arm & 1 \\
\hline
\end{tabular}

Three different materials for common cooking pots were selected for this study. These materials include stainless steel, iron and aluminium. The pots were painted black for optimum heat absorption. The covers of these pots were perforated at the top to allow the entry on a thermocouple during performance evaluation.

Fig. 1a-c shows the parabolic solar cooker with iron, aluminium and stainless steel pot, respectively. The dish has a depth of $9 \mathrm{~cm}$ and a diameter of $33.9 \mathrm{~cm}$. The pot was positioned at the focal point of the parabolic reflector. The focal point is $31.2 \mathrm{~cm}$, while the dish is adjustable in two directions.

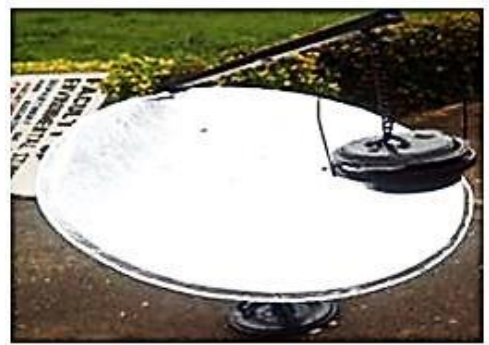

a: Parabolic solar cooker with iron pot

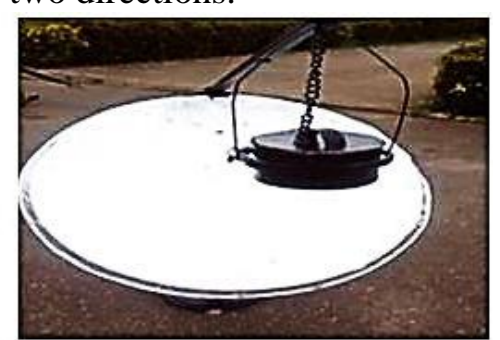

b: Parabolic solar cooker with aluminum pot

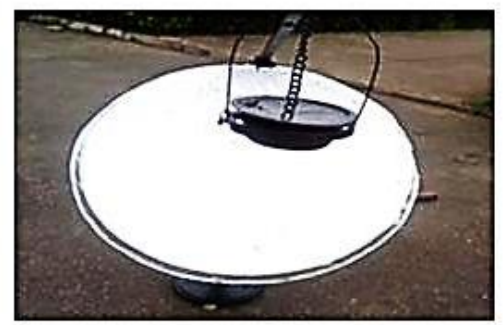

c: Parabolic solar cooker with stainless steel pot

Figure 1: Parabolic solar cooker 
The parabolic solar cooker is a direct concentrating cooker with a TV cable dish directing most of the intercepted radiation to converge at the focal point where the cooking pot was positioned. The cooker was mounted firmly on a rotating base which allows the concentrator to be positioned at the desired angle for proper tracking of the incident solar energy.

\subsection{Design of Experiments}

The procedure reported by Durakovic [34] was adopted for this study which comprises; stating the objectives, defining the response variable, determining factors, determining the experimental design type, experimentation, data analysis and interpretation.

\subsubsection{Objective}

This experimental study is aimed at identifying the performance of the parabolic concentrator solar cooker when different types of pots are used. This will also reveal whether any significant effect in the thermal performance parameters exist as a result of the different type of pots used.

\subsubsection{Experimental Design and Factor}

Asides the irradiance and ambient temperature which are uncontrollable environmental factors affect the experiment, the major factor considered for this study is the pot material. Iron, stainless steel and aluminium were considered in this study due to their difference in thermal conductivity and specific heat capacity. Since the experiment has only one factor, a simple comparative experiment was adopted; hence, ANOVA can be used for analysis [34].

\subsubsection{Experimentation}

The performance of the solar cooker was evaluated by carrying out stagnation test. Experiments were conducted at the College of Engineering and Technology, Olabisi Onabanjo University.

A. Instrumentation and Setup: The instruments used for this experiment are; thermocouples, multi-channel temperature logger and solar meter. Their specifications are as follows;

[a] Solar meter: Dr Meter Solar Power Meter SM206 was used. It has a range of $0.1-3999 \mathrm{~W} / \mathrm{m}^{2}$ and an accuracy of $\pm 10 \mathrm{~W} / \mathrm{m}^{2}$ with a sampling time of 0.25 seconds.

[b] Temperature logger: REED Thermometer SD-947 was used (Fig. 2). It accepts different thermocouples and has a range of $-100^{\circ} \mathrm{C}-1300^{\circ} \mathrm{C}$ with an accuracy of $\pm 1^{\circ} \mathrm{C}$.

[c] Thermocouples: K-type thermocouples were used. It has a temperature range of $-200^{\circ} \mathrm{C}-1250^{\circ} \mathrm{C}$.

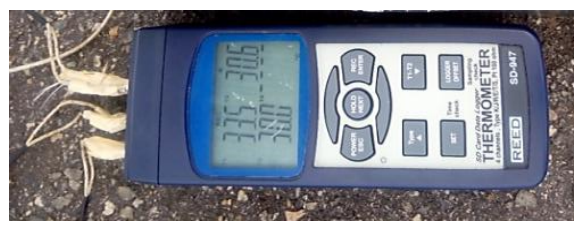

Figure 2: Temperature logger with thermocouples

The solar cooker was set up in an open area facing the direction of the sun. Care was taken to ensure that shadow was not cast on the surface of the cooker. The hot junction of the thermocouples was fixed inside the pot, while the other ends were connected to the multichannel temperature logger. The ambient air temperature was also recorded on a different channel on the multichannel temperature logger. Fig. 3 shows the experimental set up. 


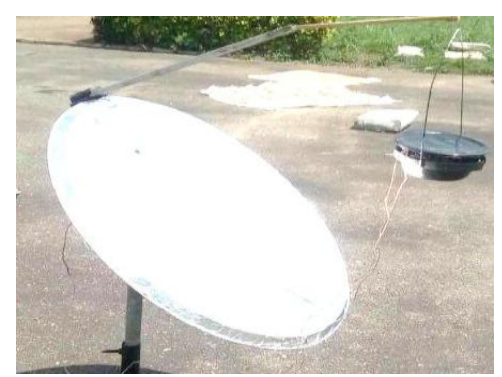

Figure 3: Experimental setup

B. Experimental Procedure: The no-load test was carried out on a clear day before 10 am with the following steps:

1. The temperatures of the inside and outer walls of the empty pot and the ambient were recorded at 30 seconds interval using the multi-channel temperature logger.

2. The intensity of solar radiation was measured using a digital solar meter. The readings were taken at the level of the solar cookers within 10 minutes interval.

3. The experiment lasted till the intensity of solar radiation dropped from the peak value.

The experiment was carried out for the three pots on different days.

\subsubsection{Response Variables}

Standard stagnation temperature (SST) and the rate of change of temperature were estimated from the results of the stagnation test.

1. Standard Stagnation Temperature (SST): The stagnation temperature gives an understandable figure for the maximum possible temperature achievable by a cooker under a specific set of conditions. This test was conducted using a dry, empty cooking vessel with two thermocouple leads fixed such that they measured the air temperature roughly in the centre of the cooking pot and the outer wall of the pot. The standard stagnation temperature is simply given by (2):

$$
S S T=700\left(\frac{T_{S}-T_{\text {air }}}{I_{o}}\right)
$$

Where $\mathrm{T}_{\mathrm{s}}\left({ }^{\circ} \mathrm{C}\right), \mathrm{T}_{\text {air }}\left({ }^{\circ} \mathrm{C}\right)$ and $\mathrm{I}_{\mathrm{o}}\left(\mathrm{W} / \mathrm{m}^{2}\right)$ are the stagnation temperature, ambient temperature and the intensity of solar radiation, respectively.

2. Rate of change of temperature: The rate of change of the stagnation temperature was estimated per minute. This estimation was necessary so as to note the behaviour of the cooking pots under the prevalent environmental conditions. This was estimated from (3).

$$
\frac{T_{s 2}-T_{S 1}}{\Delta t}
$$

Where $\mathrm{T}_{\mathrm{S} 1}$ and $\mathrm{T}_{\mathrm{S} 2}$ are the stagnation temperatures at state 1 and $2\left({ }^{\circ} \mathrm{C}\right)$ respectively, while $\Delta \mathrm{t}$ is the time difference between these two states ( $\mathrm{min}$ ).

\subsection{Data Analysis and Interpretation}

The data collected were presented using different descriptive statistical methods which shows the variation in performance of the different pots in the solar cooker. Analysis of variance (ANOVA) was carried out to investigate the significant difference between the performances of each of the pots in the solar cooker based on the result of the stagnation test.

\section{Results and Discussion}

\subsection{Solar Radiation Intensity}

Fig. 4 shows the change in the intensity of solar radiation during the experiments. When the test was carried out on the Iron pot, an average solar radiation of $400 \mathrm{~W} / \mathrm{m}^{2}$ was observed. The solar radiation intensity during the test with stainless pot ranged from $400-1200 \mathrm{~W} / \mathrm{m}^{2}$. During the test with aluminium pot, the solar radiation ranged from $195-1100 \mathrm{~W} / \mathrm{m}^{2}$. This result shows that the solar radiation was not uniform when the pots were inuse, hence comparing the three will be difficult without standardizing their performance. A standardized stagnation temperature (SST) will thus be required. 


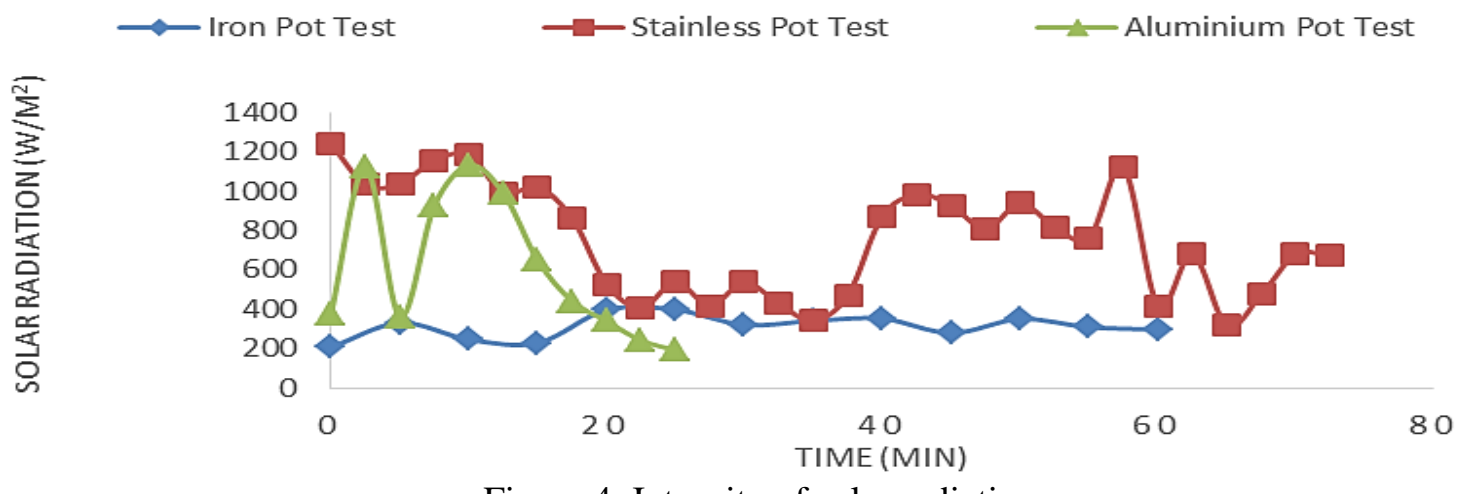

Figure 4: Intensity of solar radiation

\subsection{Stagnation Temperature}

Fig. 5 to 7 shows the stagnation temperature of the iron, aluminium and stainless steel pots respectively. Fig. 5 shows that after 10 minutes, the maximum temperatures attained by the inside and the outer wall of the iron pot were 68 and $65^{\circ} \mathrm{C}$, respectively.

The average temperature of the ambient air was around $30{ }^{\circ} \mathrm{C}$. Fig. 6 shows a clear distinction between the temperature profile of the inside and the outer wall of the aluminium pot. When the average ambient temperature was $31^{\circ} \mathrm{C}$, the temperature inside the pot attained a peak of around $80{ }^{\circ} \mathrm{C}$, while the outer wall was around $65{ }^{\circ} \mathrm{C}$. These values were attained after 13 minutes. This performance is better than when iron pot was used because of the higher specific heat capacity of aluminium. The performance of stainless steel pot in the parabolic solar cooker is similar to that of aluminium pot in terms of the difference in the temperature inside the pot and the outer wall of the pot. The only difference is that aluminium pot attained a higher temperature faster than the steel pot. Stainless steel pot attained a peak of 82 and $80{ }^{\circ} \mathrm{C}$ for inside the pot and outer walls of the pot after 45 minutes (Fig. 7). This also occurred when the average ambient temperature was $31{ }^{\circ} \mathrm{C}$.

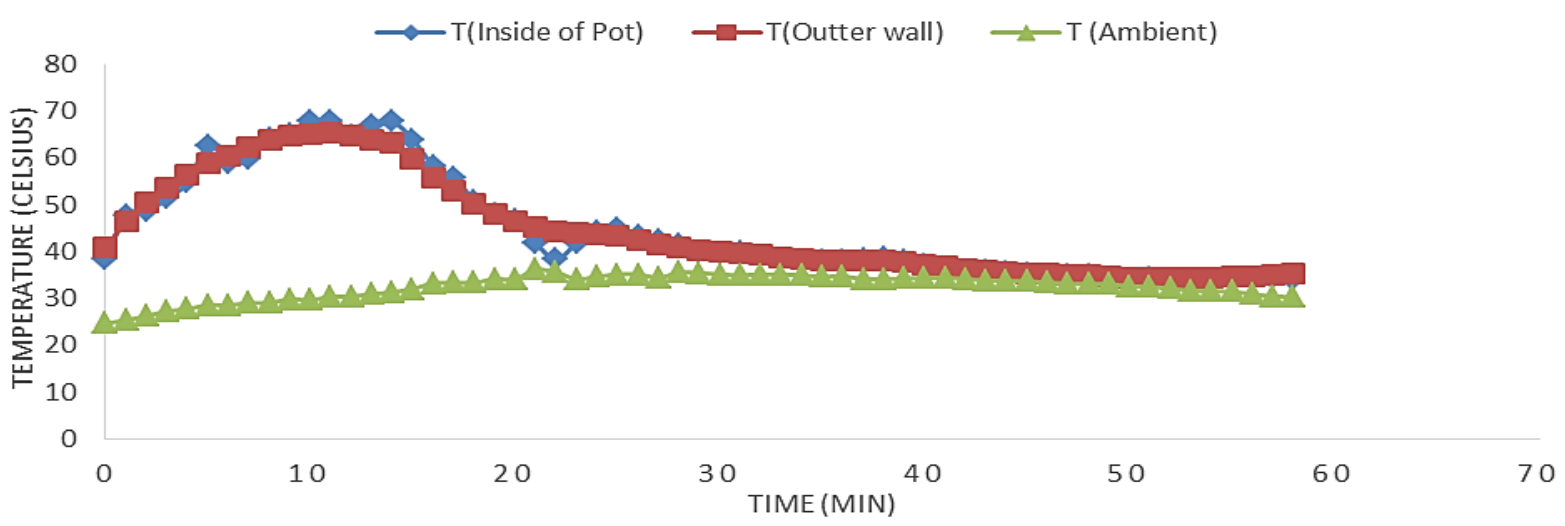

Figure 5: Stagnation temperature with an iron pot

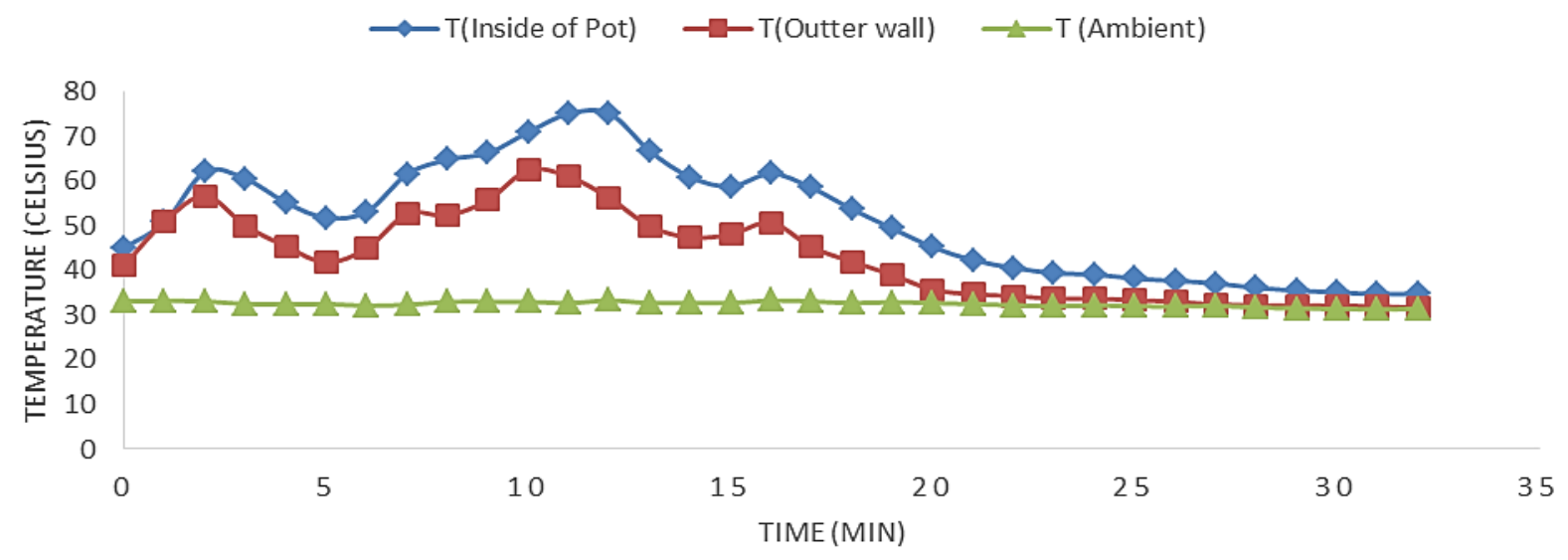

Figure 6: Stagnation temperature with an aluminium pot 


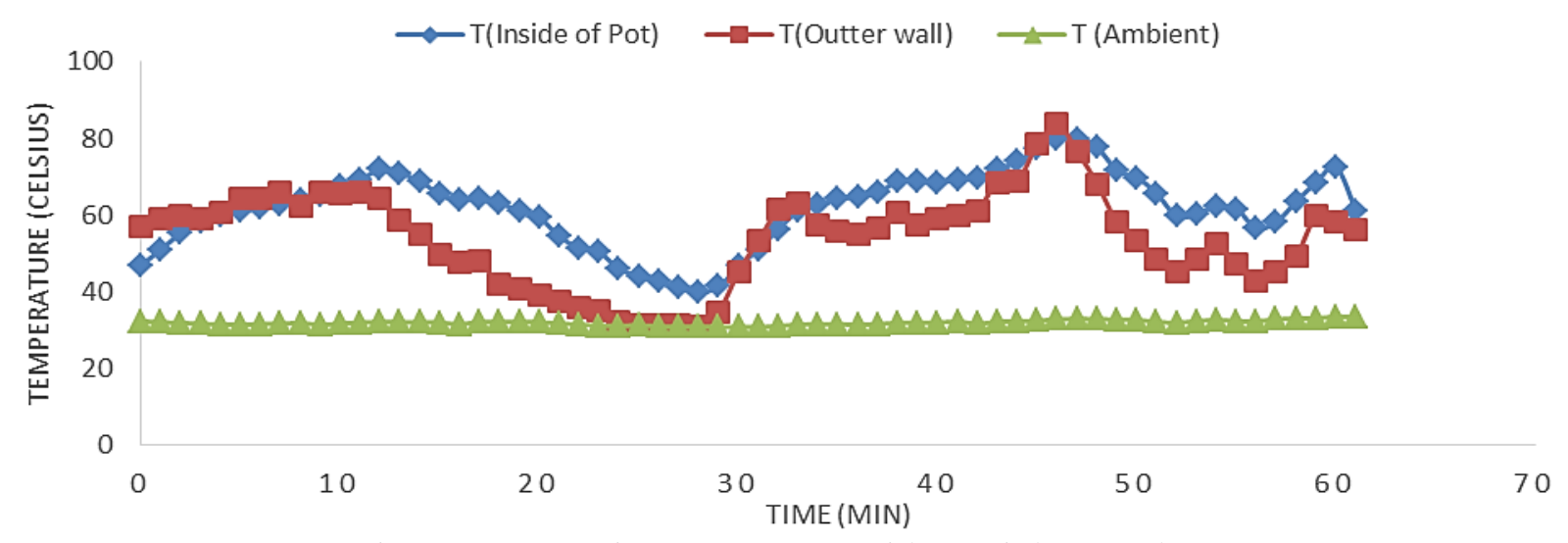

Figure 7: Stagnation temperature with a stainless steel pot

Table 2 shows the result of the analysis of variance (ANOVA) conducted on the stagnation temperature. Since the p-value is less than 0.05 , it implies that there was a significant difference between the stagnation temperatures of the inside of the pots. So many factors could cause this difference such as the intensity of solar radiation, wind speed, the direction of solar radiation and the type of pots used.

Table 2: ANOVA of stagnation temperature

\begin{tabular}{lllll}
\hline Source of Variation & SS & DF & Mean & P-value \\
\hline Between Pots & 9030.9 & 2 & 4515.4 & $7 \mathrm{E}-14$ \\
Within Pots & 18297.8 & 151 & 121.2 & \\
Total & 27328.7 & 153 & & \\
\hline
\end{tabular}

\subsection{Standard Stagnation Temperature (SST)}

Fig. 8 - 10 show the standard stagnation temperature (SST). It was observed that under ideal conditions and at an average solar radiation of $700 \mathrm{~W} / \mathrm{m}^{2}$, the inside of the iron pot, aluminium pot and stainless steel pot will attain maximum temperatures of 110,81 and $75{ }^{\circ} \mathrm{C}$ above the ambient air temperature respectively. Iron pots will perform better since its rate of heat loss to the environment will be the lowest. For the outer wall of the pots, the maximum SST attained are 100,57 and $59{ }^{\circ} \mathrm{C}$ for iron, aluminium and stainless steel pots, respectively.

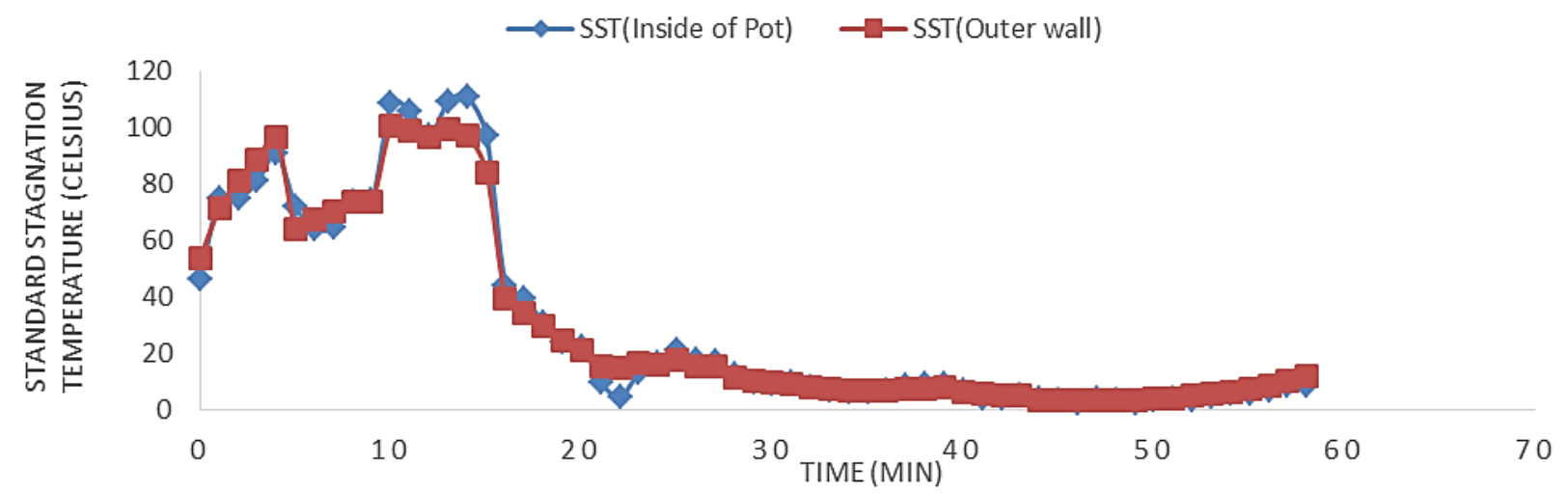

Figure 8: SST with an iron pot 


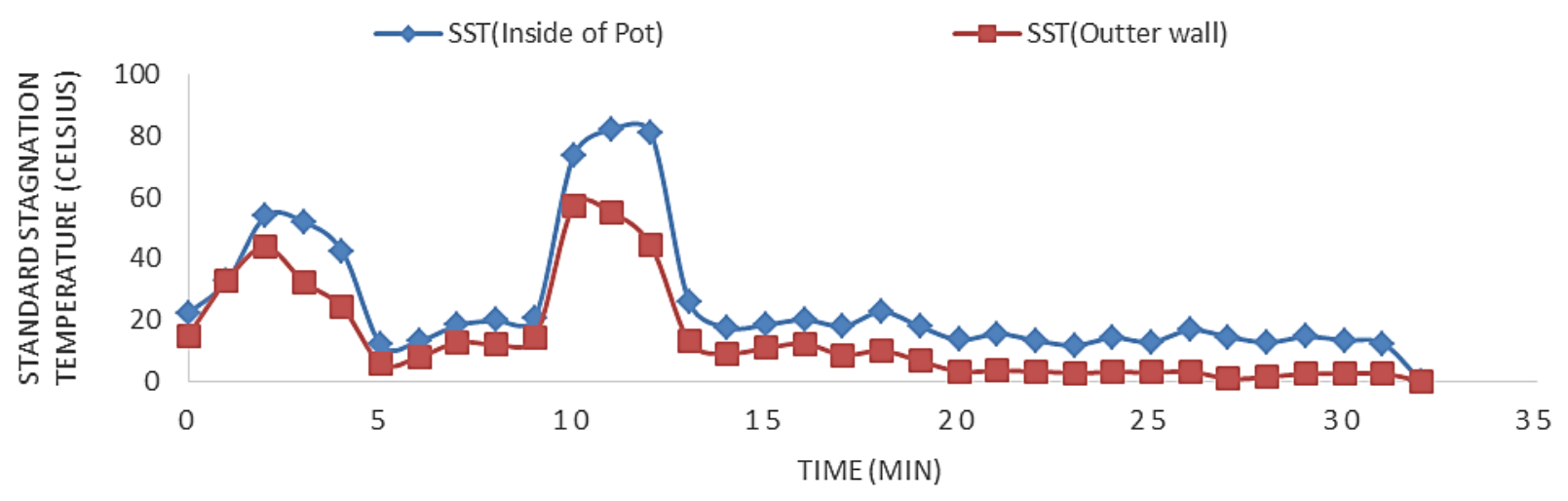

Figure 9: SST with an aluminium pot

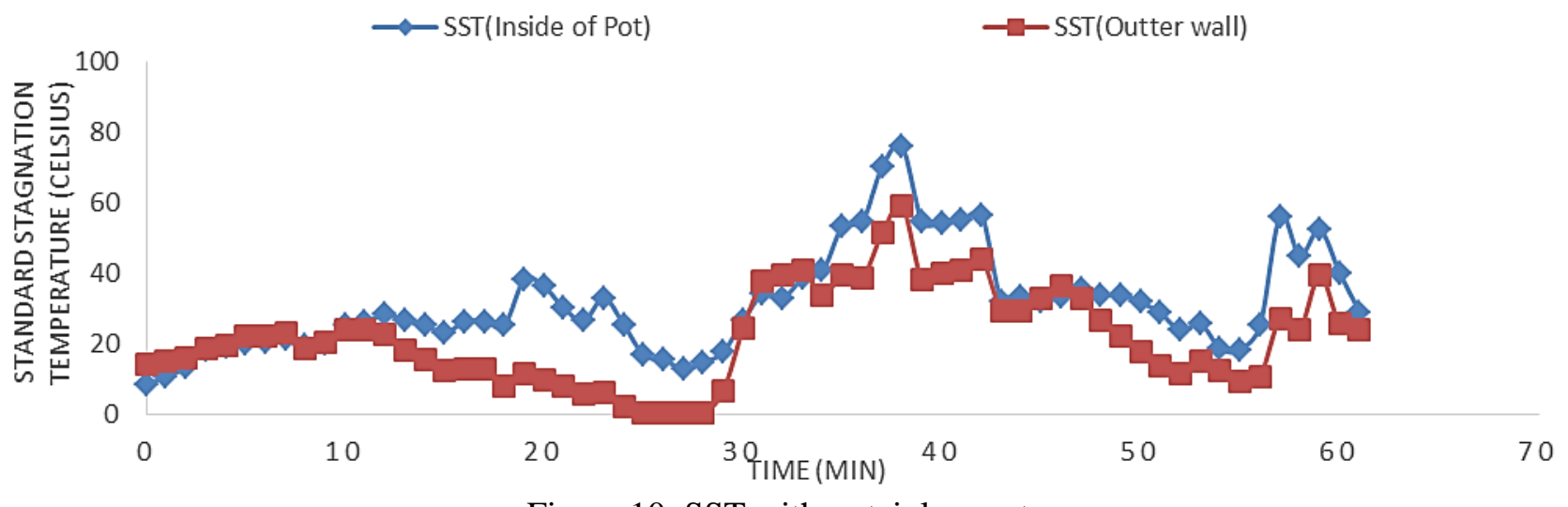

Figure 10: SST with a stainless pot

\subsection{Temperature Change}

Fig. 11, 12 and 13 show the change in temperature of the iron, aluminium and stainless steel pots respectively. The temperature inside of the iron pot did not rise above $9{ }^{\circ} \mathrm{C} / \mathrm{min}$, while its outer wall had a maximum temperature change of $6{ }^{\circ} \mathrm{C} / \mathrm{min}$. During the stagnation test, the iron pot had a maximum temperature drop of 6 and $4{ }^{\circ} \mathrm{C} / \mathrm{min}$ for the inside of the pot and outer walls respectively (Fig. 11).

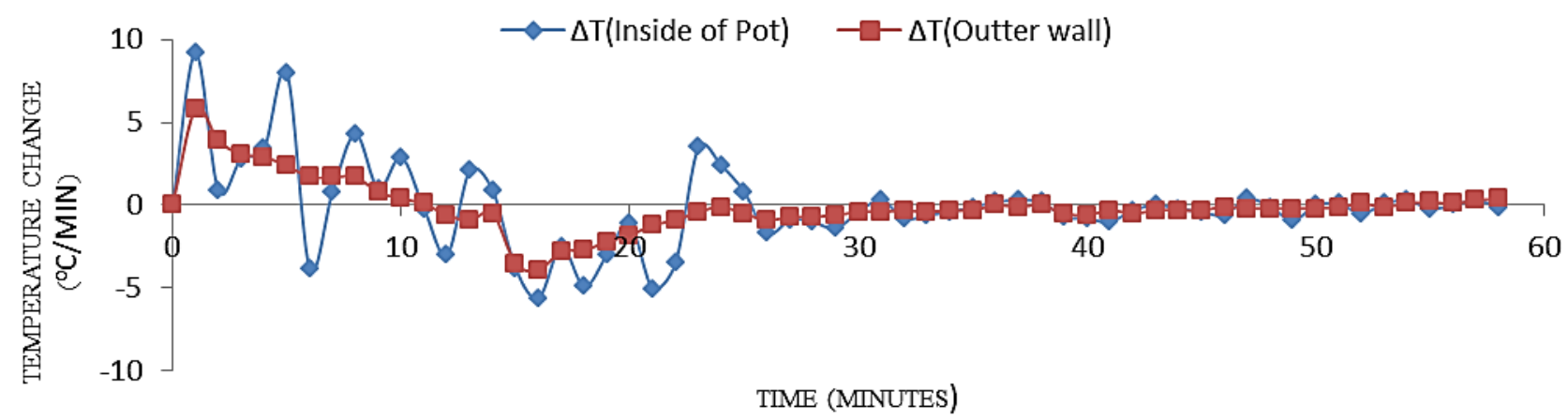

Figure 11: Temperature change of iron pot

From Fig. 11, the temperature inside the aluminium pot had a maximum value of $12{ }^{\circ} \mathrm{C} / \mathrm{min}$ while its outer wall had a maximum temperature change of $10{ }^{\circ} \mathrm{C} / \mathrm{min}$. During the stagnation test, the iron pot had a maximum temperature drop of 8 and $6{ }^{\circ} \mathrm{C} / \mathrm{min}$ for the inside and outer walls respectively. These high values of heat loss and gain are clearly due to the thermal properties of aluminium. 


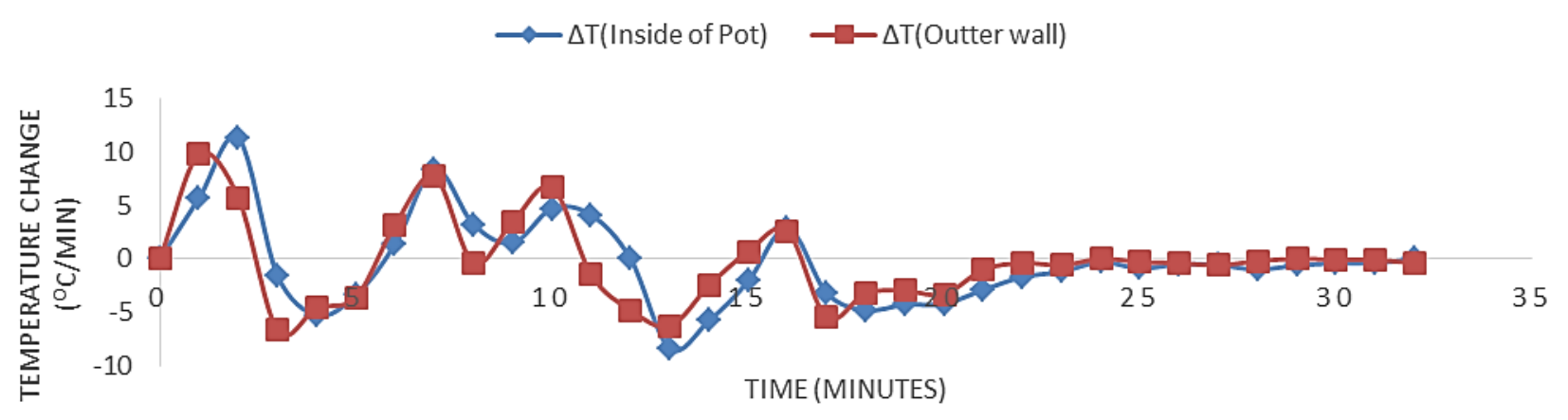

Figure 12: Temperature change of aluminium pot

The temperature inside the stainless steel pot did not rise beyond $10{ }^{\circ} \mathrm{C} / \mathrm{min}$, while its outer wall had a maximum temperature change of $5{ }^{\circ} \mathrm{C} / \mathrm{min}$. During the stagnation test, the stainless steel pot had a maximum temperature drop of 10 and $5{ }^{\circ} \mathrm{C} / \mathrm{min}$ for the inside and outer walls respectively. The high variation in the temperature change inside the pot and at the outer wall was due to the low heat transfer from the outer wall to inside the pot.

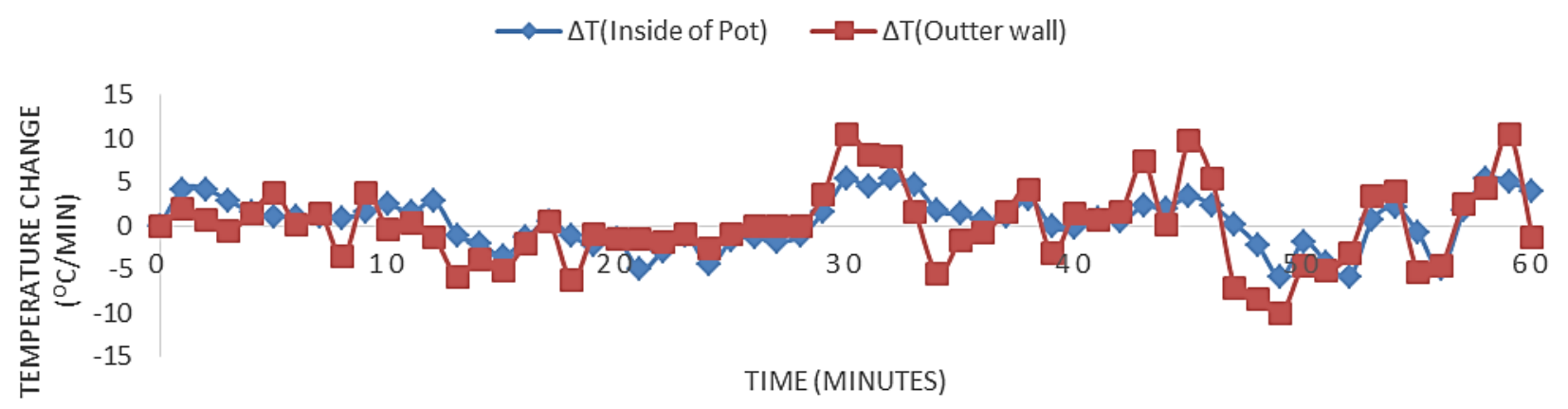

Figure 13: Temperature change of stainless steel pot

Table 3 shows that there is no significant difference between the rates of change of temperature per minute between the pots.

Table 3: ANOVA of temperature change

\begin{tabular}{lllll}
\hline Source of Variation & SS & DF & Mean & P-value \\
\hline Between Pots & 13.6 & 2 & 6.8 & 0.5 \\
Within Pots & 1397.8 & 150 & 9.3 & \\
Total & 1411.3 & 152 & & \\
\hline
\end{tabular}

\section{Conclusion}

A television cable dish was adapted into a parabolic concentrator solar cooker using readily available and cheap materials. The major technical detail needed is the determination of the dish's focal point so as to locate the pot or any other heat output element. Experimental data were collected for different types of pot (iron, aluminium and stainless steel). The performance of the parabolic solar cooker was investigated in terms of testing the stagnation of each pot. An SST above $60{ }^{\circ} \mathrm{C}$ was attained within 30 minutes during an average solar radiation of $700 \mathrm{~W} / \mathrm{m}^{2}$. Although extensive evaluation is still required, this study shows that this system can be adapted for low-temperature applications like pasteurization, sterilization, household water heating, etc. Further work can be carried out on the integration of heat storage materials to this system so as to reduce the high rate of heat loss when there is a drop in solar radiation and to also make the system usable at night. 


\section{References}

[1] N.J. Ekins-Daukes, "Solar energy for heat and electricity: the potential for mitigating climate change," Grantham Institute for Climate Change; Briefing Paper 1, pp. 1-12, 2009.

[2] Durakovic and M. Torlak, Experimental and numerical study of a PCM window model as a thermal energy storage unit" International Journal of Low-Carbon Technologies, vol. 12, no. 3, pp 272-280, 2017.

[3] R. Rahul, A. Tiwari, and S. Chakravarty. (2011) Team Anshuk - Solar Cooker. [Online]. www.engineeringforchange.org/uploads/activity/22/22/448/1325007307434/SudarshanChakrvarthy.p $\underline{\mathrm{df}}$

[4] University of Califonia. (2005) K-12 Environmental Education. [Online]. solar.ucsd.edu/education/TX/TX lesson 12 SolarCooking worksheet.pdf

[5] Shahzad Aamir, Kanwal Teyyiba, and He Mao-Gang, "Design and Development of Efficient Domestic Electric Cum Solar," Journal of Basic \& Applied Sciences, vol. 9, pp. 296-301, 2013.

[6] A.M. Kofa. (2012) Solar Energy for Sustainable Power Supply in Nigeria. [Online]. www.sweetcrudereports.com/2012/12/25/solar-energy-for-sustainable-power-supply-in-nigeria/

[7] A. Ejeh and I.N. Itodo, "A Model for Determining Solar Radiation for Markudi Location, Nigeria," Nigeria Journal of Solar Energy, vol. 20, pp. 24-27, 2010.

[8] M. Pendieu Kwaye, J. Bendfeld and N. Anglani, "Assessment of renewable energy resources in cameroon and special regards on energy supply," 2015 5th International Youth Conference on Energy (IYCE), Pisa, 2015, pp. 1-7.

[9] A. Belhamadia, M. Mansor and M.A.Younis, "Assessment of Wind and Solar Energy Potentials in Malaysia", 2013 IEEE Conference on Clean Energy and Technology (CEAT), Langkawi, 2013, pp. 152-157.

[10] C. Sorapipatana, "An assessment of solar energy potential in Kampuchea", Renewable and Sustainable Energy Review, vol. 14, no.8, pp. 2174-2178, 2010.

[11] M.F. Ariza Taba, M. Mwanza, N.S. Çetin and K. Ülgen, "Assessment of the energy generation potential of photovoltaic systems in Caribbean region of Colombia", Periodical of Engineering and Natural Sciences, vol. 5, no.1, pp. 55-60, 2017.

[12] M. Mwanza, J. Chachak, N.S. Çetin and K. Ülgen, "Assessment of Solar Energy Source Distribution and Potential in Zambia", Periodical of Engineering and Natural Sciences, vol. 5, no.2, pp. 103-116, 2017.

[13] J. Chikaire et al., "Solar Energy Applications for Agriculture," Journal of Agricultural and Veterinary Sciences, vol. 2, pp. 58-62, 2010.

[14] M. Mwanza, M. Kaoma, C.K. Bowa, N.S. Çetin and K. Ülgen, "The Potential of Solar Energy for Sustainable Water Resource Development and Averting National Social Burden in Rural Areas of Zambia", Periodical of Engineering and Natural Sciences, vol. 5, no.1, pp. 1-7, 2017.

[15] J.K. Yohanna and V.I. Umogbai, "Solar Energy Potentials and Utilization in Nigeria Agriculture," Journal of Environmental Issues and Agriculture in Developing Countries, vol. 2, no. 2\&3, pp. 10-21, 2010.

[16] Nathan Rona, Solar Air-Conditioning Systems, eBook ed. Göteborg, Sweden: Chalmers University of Technology, 2004.

[17] S.A. Kalogirou, "Solar Thermal Collectors and Applications," Progress in Energy and Combustion Science, vol. 30, pp. 231-295, 2004.

[18] S.R. Bello and S.O. Odey, "Development of Hot Water Solar Oven for Low Temperature Thermal Processes," Leonardo Electronic Journal of Practices and Technologies, vol. 14, pp. 73-84, 2009. 
[19] W.K.S. Hussein, "Solar Energy Refrigeration by Liquid-Solid Adsorption Technique," Department of Clean Energy and Energy Conservation Engineering, An-Najah University, Nablus - Palestine, MSc. Thesis 2008.

[20] Joshua Folaranmi, "Design, Construction and Testing of a Parabolic Solar Steam Generator," Leonardo Electronic Journal of Practices and Technologies, vol. 14, pp. 115-133, 2009.

[21] Armeda VanDam. (2005) How to make a Parabolic Solar Cooker. [Online]. http://forest.mtu.edu/pcforestry/resources/studentprojects/solarcookers.htm

[22] M. Gwani, G.A. Abubakar, M. Abbas, M. Na Allah, and J. Danyaro, "Design, Fabrication and Experimental Study of Solar Parabolic Dish Concentrator for Remote Area Application," International Journal of Sciences: Basic and Applied Research, vol. 23, no. 1, pp. 230-241, 2015.

[23] I.L. Mohammed, "Design and Development of a Parabolic Dish Solar Thermal Cooker," IJERA, vol. 3, no. 4, pp. 1179-1186, 2013.

[24] Gavisiddesha, P.P. Revankar, and M.B. Gorawar, "Evaluation of Thermal Performance of Paraboloid Concentrator Solar Cooker," IJIRTS, vol. 1, no. 3, pp. 58-65, 2013.

[25] D.Y. Dasin, "Thermal Performance Testing of Parabolic Solar Cooker Using New World Standard Procedure," International Journal of Engineering Research and Technology, vol. 6, no. 3, pp. 323331, 2013.

[26] D.Y. Dasin, A.A. Asere, and D. Habou, "Development of Convective Heat Transfer Correlations in the Cooking Pot of a Parabolic Concentrator Solar Cooker," Nigerian Journal of Solar Energy, vol. 22, pp. 1-6, 2011.

[27] H. Dandakouta, K. Adeyemi, G. Egbo, and A.A. Asere, "Compound Parabolic Concentrating Solar Cooker and the Influence of a Flat Reflector Booster on its Performance," Nigerian Journal of Solar Energy, vol. 19, no. 2, pp. 1-5, 2006.

[28] B.J.C. Anyanwu, A.A. Ejem, and I.M. Nwokeocha, "Deregulation, Globalisation and Current Issues in the Electronic Media in Nigeria," News Media and Mass Communication, vol. 41, pp. 15-23, 2015.

[29] Ezell. (2016) Need to Recycle Your Satellite TV Dish? Earth 911. [Online]. https://earth911.com/uncategorized/looking-to-recycle-your-satellite-tv-dish-read-this-first/

[30] P. Guerra. (2014) Bee Investigator: It's up to property owners to remove old satellite dishes. The Modesto Bee. [Online]. http://www.modbee.com/news/local/article3172203.html

[31] G.O. Prado, L.G.M. Vieira, and J.J.R. Damasceno, "Solar dish concentrator for desalting water," Solar Energy, vol. 136, pp. 659-667, 2016.

[32] O. Sandru. (2008) The Green Optimistic: How to Build a Solar Furnace from a Satellite Dish. [Online]. $\quad$ https://www.greenoptimistic.com/how-to-build-solar-furnace-satellite-dish20080908/\#.XA2yJtVKi00

[33] H. Hijazi, O. Mokhiamar, and O. Elsamni, "Mechanical design of a low cost parabolic solar dish concentrator," Alexandria Engineering Journal, vol. 55, no. 1, pp. 1-11, 2016.

[34] B. Durakovic, "Design of Experiments Application, Concepts, Examples: State of the Art", Periodical of Engineering and Natural Sciences, vol. 5, no.3, pp. 421-439, 2017. 